\title{
Effect of the particle size and the liquid content on the shear behaviour of wet granular material
}

\author{
H. Louati *, D . O u l a h n a , A. d e R y c k \\ Centre Rapsodee, Mines Albi, CNRS, Université de Toulouse, Campus Jarlard, F-81013 Albi Cedex 09, France
}

Keywords:

Particle size

Liquid content

Capillary force

Tensile strength

Shear stress

Wet granular material

\begin{abstract}
A B S T R A C T
The size of particle is a relevant parameter in the study of the granular material behaviour. For wet granular materials, it affects the capillary force and the number of liquid bridges. We present quantitative and qualitative investigations of the effect of the particle size on the steady-state shear behaviour of partially wet granular material. Two sizes of glass beads have been used: $12-40 \mu \mathrm{m}$ and $70-110 \mu \mathrm{m}$ in diameter and the shear behaviour was studied using an annular shear cell. The results show different regimes of the shear-normal stresses relationship depending on the particle size, with a general increase of the magnitude of the shear stress for a decrease in the particle size.

Most studies of wet granular material behaviour have focused on the pendular state of saturation with liquid bridge formed between particles. In this study, the states of saturation are explored going up to completely filling the space between beads of $70-110 \mu \mathrm{m}$. Different regimes are identified depending on the liquid fraction and the applied normal stress. A theoretical approach was used to estimate the tensile strength for the different states of saturation. An agreement between both experimental and theoretical data was observed and discussed.
\end{abstract}

\section{Introduction}

The granular material is an assembly of discrete individual particles, with a collective behaviour due to the interactions between them. The particle size is one of the relevant properties, which affect significantly the behaviour of the granular material. For particle smaller than hundred of microns, the inter-particle forces such as the Van-der-Waals forces are generally greater than the gravitational forces [21]. This changes the behaviour of the granular material from a non-cohesive behaviour to a cohesive one. With the addition of a wetting liquid, the capillary force dominates in magnitude the Van-der-Waals force.

At small or moderate volume of liquid content, $[8,18]$ observed the yielding of the granular material at low stress conditions, by looking at the angle of repose or the tensile strength of a pile. The yield strength increases first, for liquid content of about $1 \%$ of the total volume, then saturates till a liquid content of $15 \%$. This saturation is explained by the Laplace pressure in the liquid bridges, which saturates with the volume of liquid since the curvature of the liquid-air interface is bounded by the one imposed by the particle geometry.

Recently, we have investigated the increase of the shear resistance due to the presence of a wetting liquid in steady-state conditions, in shear mixers [14]. In order to better control the sheared plane and to quantitatively analyse the shear stress, an annular shear cell was later

\footnotetext{
* Corresponding author.

E-mail address: Haithem.louati@mines-albi.fr (H. Louati).
}

used to carry out the experiments for a large range of applied normal stress from about $0.3 \mathrm{kPa}$ to $12 \mathrm{kPa}$ [10]. We have investigated the shear behaviour of $70-110 \mu \mathrm{m}$ glass beads in the pendular regime. The results give the variation of the shear stress at steady-state as a function of the normal stress for a wide range of liquid fraction. A non-linear relationship of the shear stress-normal stress was observed, implying different regimes. In particular, an apparent cohesion appeared at high normal stress and high liquid fraction, while it remains negligible at low normal stress. However, the shear stress is proportional to the normal stress when the latter is small enough, with an apparent friction coefficient increasing with the liquid fraction.

The increase of the shear resistance in steady-state conditions was explained by a model where the number of capillary bridges renewed during shearing are dependent on the rearrangements of the particle bed and hence on its density, which is affected by the normal stress applied [10]. In this paper, we go further, and we investigate the effect of smaller particle size on the shear behaviour of partially wet granular material in steady-state for different normal stresses and liquid fractions up to completely filling the inter-particle spaces.

\section{Materials and methods}

The material used in this study consists of glass beads provided by Sovitec $®$. The glass beads are used in the experiments as supplied without any surface treatments, but sieved to obtain narrow size distributions. Two different sizes of glass beads were used in this study: 
$70-110 \mu \mathrm{m}$ and $12-40 \mu \mathrm{m}$ in diameter. These sizes are chosen small to enhance the effect of the capillary forces vis-à-vis the gravitational forces. The spreads of both particle size distributions may be evaluated around 0.2 and 0.6 if supposed log-normal distributed, or the coefficient of uniformity is lower than 1.5 and 3.3 respectively [22]. Following this work and the one by Dexter \& Tanner [4], we conclude that the packing density for non-cohesive granular materials may increase by 0.02 to 0.05 for the glass beads with a wider distribution (12-40 $\mu \mathrm{m})$ compared to the $70-110 \mu \mathrm{m}$ glass beads. The expected increase is weak and the observations reported in Section 3.1.1 indicate that the Van-der-Waals forces for the 12-40 $\mu \mathrm{m}$ make the smaller material to be in fact less packed.

The glass beads were wetted using polyethylene glycol of $400 \mathrm{~g}$ molar weight (PEG 400) provided by Alfa Aesar. This liquid has been chosen since it wets well the glass beads and has also a low volatility compare to water, which helps to work with small liquid fractions with small evaporation rate. The characteristics of the PEG 400 are given in Table 1. The viscous forces may play an important role on the dynamic of the glass beads. We compute a capillary number, $\mathrm{Ca}$, in order to quantify the viscous effect compared to the capillary effect. The viscous effect is considered as relevant if $\mathrm{Ca}>1$. This number is given as $C a=\mu_{l} v_{p, p} / \gamma$, where $\mu_{l}$ is the dynamic viscosity of liquid, $\gamma$ is the surface tension and $v_{p, p}$ is the relative particle-particle velocity. The latter is calculated based on the Stokes velocity as $v_{p, p}=\left(2 R^{2}\left(\rho_{p}-\right.\right.$ $\left.\left.\rho_{\mathrm{g}}\right) g\right) /\left(9 \mu_{\mathrm{g}}\right)$, where $\mu_{\mathrm{g}}$ is the dynamic viscosity of ambient gas, $\rho_{p}$ and $\rho_{g}$ are the density of particles and the density of ambient gas respectively [23]. For our experiments, we have $C a=0.04$ for $12-40 \mu \mathrm{m}$ glass beads and $C a=0.9$ for $70-110 \mu \mathrm{m}$ glass beads. Furthermore, the viscous effect not only depends on the liquid properties but also on the wet powder processing parameters. The behaviour of the wet glass beads is studied here using an annular shear test (see more details about the device in Section 2.2.2). Thus, we compute another dimensionless number, which is the time scale for bridge filling relative to the shear time. The viscous effect should be considered if the time scale is in the order of a shear time [23]. The obtained values for the dimensionless number do not exceed 0.001 for both particle sizes. Thus, the viscous effect is considered less relevant in this work and we will focus only on the capillary effect.

The glass beads were mixed with various quantities of PEG 400 using a Kenwood planetary mixer (1200 g of glass beads during $20 \mathrm{~min}$ ). The procedure of mixing is important to ensure a homogeneous distribution of liquid in the granular material, especially at low liquid fractions. The fraction of liquid is expressed as a volume ratio $\left(V_{R} \%=\right.$ volume of liquid / total volume of particles). The fractions of liquid investigated in this study vary from $0.01 \%$ to $20 \%$ for the partially state of saturation, so-called pendular state. It is increased then from $20 \%$ to $60 \%$ in order to investigate more saturation states (funicular and potentially capillary states).

\subsection{Characterisation of the glass beads properties}

\subsubsection{The particle surface analysis}

The surface of the glass beads, as supplied, was observed using two techniques: the Scanning Electron Microscope (SEM) and the AtomicForce Microscopy (AFM). The SEM images of the glass beads 12-40 $\mu \mathrm{m}$ and $70-110 \mu \mathrm{m}$ show a rough surface. The observed

\section{Table 1}

Properties of the polyethylene glycol 400: density, viscosity, surface tension and angle of contact with the glass beads.

\begin{tabular}{ll}
\hline Properties of PEG 400 & Values \\
\hline Density $\left(\mathrm{g} / \mathrm{cm}^{3}\right)$ at $20{ }^{\circ} \mathrm{C}$ & 1.128 \\
Viscosity $(\mathrm{mPa} \cdot \mathrm{s})$ at $25{ }^{\circ} \mathrm{C}$ & 99.01 \\
Surface tension $(\mathrm{mN} / \mathrm{m})$ at $23.5{ }^{\circ} \mathrm{C}$ & 56.74 \\
Angle of contact $\left({ }^{\circ}\right)$ (with the glass beads) & $\sim 0$ \\
\hline
\end{tabular}

roughness is caused by the impurities adhered to the surface and also due to manufacturing defects in the form of microscopic cavities or bumps. Several SEM observations were performed in order to evaluate the size of the asperities. From the obtained images (see Fig. 1), an average height of the asperities is observed to be in the range of 1 to $2 \mu \mathrm{m}$. The AFM allows analysing the surface roughness by measuring the interactive forces between the AFM cantilever (a force tensor) and the surface of the sample. The measurements were performed with a Raman-AFM microscope, alpha300 RA, WITec GmbH. A number of glass beads were glued to a glass microscope slide and the roughness of the free surface of beads was measured using contact mode. Similar values to the one estimated by SEM were also obtained from AFM. We consider an average value of $1.5 \pm 0.5 \mu \mathrm{m}$. The formation of liquid bridges is also affected by the surface roughness and some models to estimate the capillary forces require the estimation of the size of asperities.

\subsubsection{The voidage fraction}

The voidage fraction is calculated as the volume of the void divided by the total volume of the wet granular material, which includes the volume of the glass beads, the voids and the liquid. It is expressed as a function of the densities as:

$\varepsilon_{\text {wet }}=1-\frac{\rho}{\rho_{s}} \frac{1+\mathrm{V}_{\mathrm{R}}}{1+\mathrm{V}_{\mathrm{R}}\left(\frac{\rho_{L}}{\rho_{s}}\right)}$,

where $\rho_{s}$ is the true density, measured using a helium pycnometer AccuPyc II 1330 Micromeritics $® . \rho$ is the apparent density, calculated by measuring the volume occupied by a given mass of glass beads in the measurement shear cell. $\rho_{L}$ is the density of the liquid, simply measured using a measuring tube (see Table 1 ).

The X-ray tomography is a potential technique for the analysis of the bulk properties of a granular material, in particular the voidage fraction. This technique allows by image analysis not only to estimate the voidage fraction but also to get information about the distribution of the voids in the granular bed, in particular for cohesive powder. The analysis of the glass beads of $70-110 \mu \mathrm{m}$ was performed using Phoenix Nanotom ${ }^{\circledR} \mathrm{X}$-ray tomography. A sample of glass beads was putted in a small transparent gelatine capsule of $6 \mathrm{~mm}$ in diameter and manually slightly packed to avoid large gaps due to the filling process. We performed analysis of the glass beads $70-110 \mu \mathrm{m}$, dry and wet with different liquid fractions. The use of the PEG 400 as a liquid to wet the glass beads has been an advantage since it is detected in this analysis. The technique allows to achieve a large number of radiography in different angle of the sample and to combine them in order to obtain a 3D construction of the sample. This requires the use of software capable of processing such a large number of images in a reasonable time. In this study, the voidage fraction was analysed from the 2D radiography and the images were treated using Matlab ${ }^{\circledR}$. Different images, representing different sections of the sample, were treated to estimate an average value of the voidage fraction. Further information about the image analysis will be given next.

\subsection{Characterisation of the flow behaviour of the granular material}

\subsubsection{The angle of repose}

The reduction of the particle size can increase the cohesion due to the Van-der-Waals forces in play. The increase of the cohesion of the granular material can be observed by looking at the angle of repose. We performed measurements of the angle of repose for the glass beads $70-110 \mu \mathrm{m}$ and $12-40 \mu \mathrm{m}$ in the dry case using the Hosokawa Powder Tester PT-N. The test consists in pouring the powder through a funnel with an outlet of $5 \mathrm{~mm}$ over a support of $12 \mathrm{~cm}$ diameter. After avalanches, the angle of repose of the heap can be measured. Fig. 2 shows a relatively small angle of repose for the glass beads $70-110 \mu \mathrm{m}$ with well-shaped surface of the heap. However, an irregular 

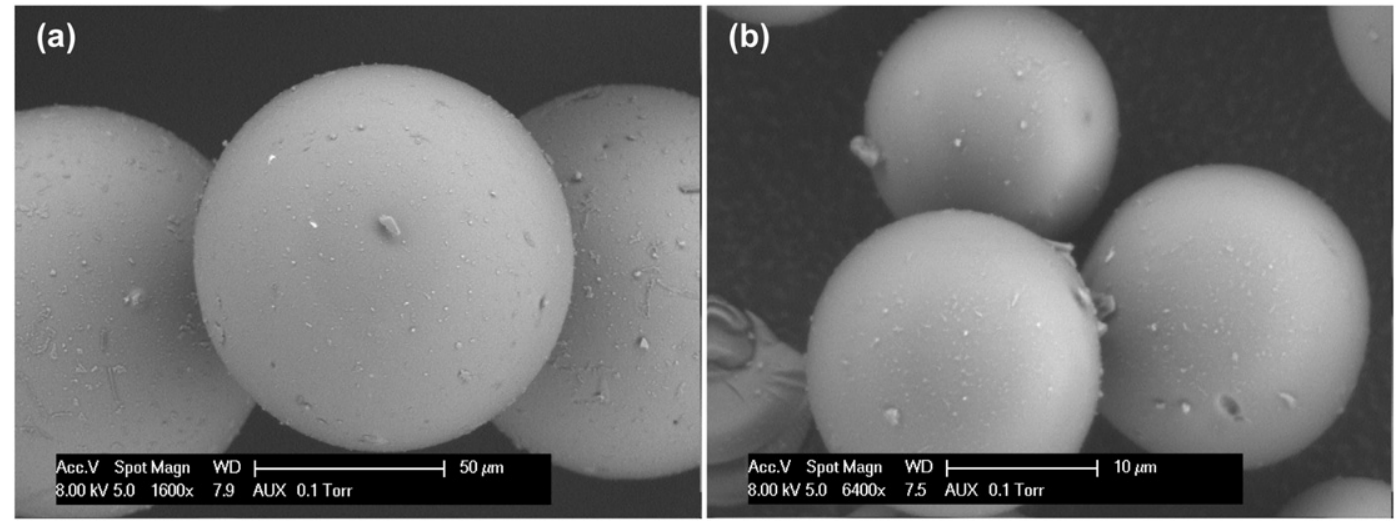

Fig. 1. Electron microscope scan images of the glass beads showing the asperities on the particle surface. (a) $70-110 \mu \mathrm{m}$ glass beads and (b) $12-40 \mu \mathrm{m}$ glass beads.

shape of the glass beads heap of $12-40 \mu \mathrm{m}$ is observed. The measured values of the angle of repose are about $24.5^{\circ}$ for the $70-110 \mu \mathrm{m}$ glass beads and around $30^{\circ}$ for the $12-40 \mu \mathrm{m}$ glass beads. We observe an increase of the angle of repose by decreasing the particle size in the dry situation and hence the estimated static friction is higher. In the next we will be investigating the effect of liquid on the apparent friction obtained from the shear test data.

\subsubsection{The shear test in steady-state conditions}

Schulze shear cell was used to study the flow properties of dry and wet glass beads (see Fig. 3). This equipment consists of an annular chamber with an inner diameter of $10 \mathrm{~cm}$ and an outer diameter of $20 \mathrm{~cm}$. More details about the geometry parameters of this device were given in [10]. To run a shear test, the chamber is filled with the sample and rotates at a constant rotational velocity, $\omega$, of $2.3 \mathrm{mrad} / \mathrm{s}$. The bottom of the chamber and the lower side of the lid are rough due to the presence of small bars, which prevent wall slippage. The shear plane occurs below the bars of the lid, therefore the weight of the particles between the bars is taken into consideration when calculating the normal stress $\sigma$ acting on the sheared surface. We used:

$\sigma=\frac{M g}{A}+\rho g h$,

where $M$ is the normal loading weight, $g$ is the gravitational constant, $A$ is the area of the lid and $h=4 \mathrm{~mm}$ is the height of the bars.

The shearing process consists of measuring the mean tangential stress $\tau$ from the torque applied by the rotating powder on the powder kept fixed together with the lid; and obtained by the two force sensors $F_{1}$ and $F_{2}$, which hold it (see Fig. 3). This measurement is repeated for various normal stresses. The relationship used to calculate the shear stress, $\tau$, as a function of $F_{1}$ and $F_{2}$ is given as:

$\tau=\frac{3\left(\mathrm{~F}_{1}+\mathrm{F}_{2}\right) l}{2 \pi\left(R_{e}^{3}-R_{i}^{3}\right)}$,

where $l$ is the distance from the axis of rotation of the shear cell and the end of a rod connected to a force sensor, $R_{e}$ and $R_{i}$ are the external and the internal radii of the shear cell respectively. The experiments were performed for the dry and wet glass beads with various liquid fractions of PEG 400. For each sample, a range of normal loads was used from $24 \mathrm{~kg}$ to $1 \mathrm{~kg}$ by removing $1 \mathrm{~kg}$ each step after tangential discharge. For a given normal load, the sample was sheared for about $1 \mathrm{~min}$. After a peak, a plateau value or an oscillatory steady-state regime is obtained. In the following, a mean value of the shear stress at steady-state is calculated from the diagram (shear stress-time) and then used to study the flow properties of dry and wet glass beads (see Fig. 3).

\section{Results and discussions}

\subsection{Effect of the particle size}

\subsubsection{Observations of the wet granular bed}

It is known from the literature that the voidage fraction of mono-size spheres decreases for an increase in the particle size. This is true for a particle smaller than a critical size value beyond which the voidage fraction becomes independent on the particle size [24]. In this study, we compare the voidage fraction of two different sizes of glass beads. In the dry case, the voidage fraction of a loose packing of glass beads in the range of $12-40 \mu \mathrm{m}$ of diameter is about 0.45 and it is bigger than
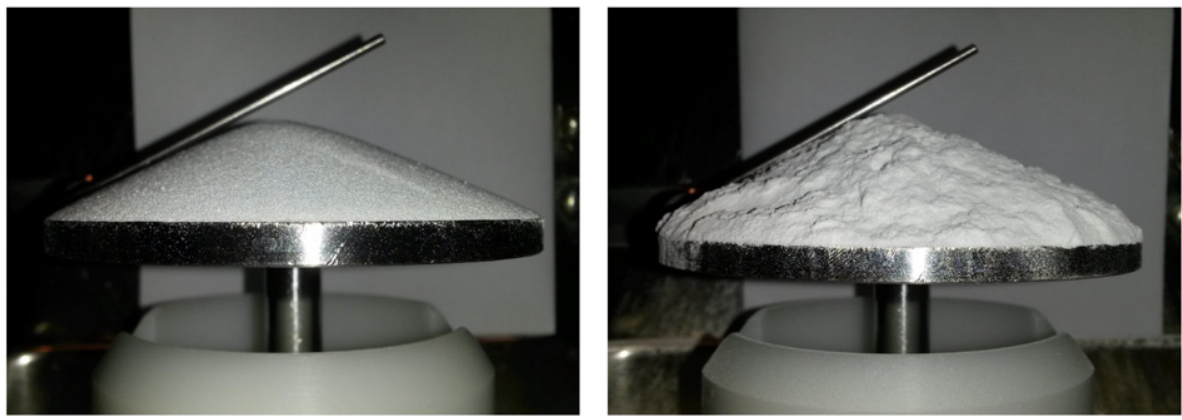

Fig. 2. Measurements of the angle of repose of dry glass beads using Hosokawa tester. (Left) glass beads of $70-110 \mu \mathrm{m}$ and (right) glass beads of $12-40 \mu \mathrm{m}$. 

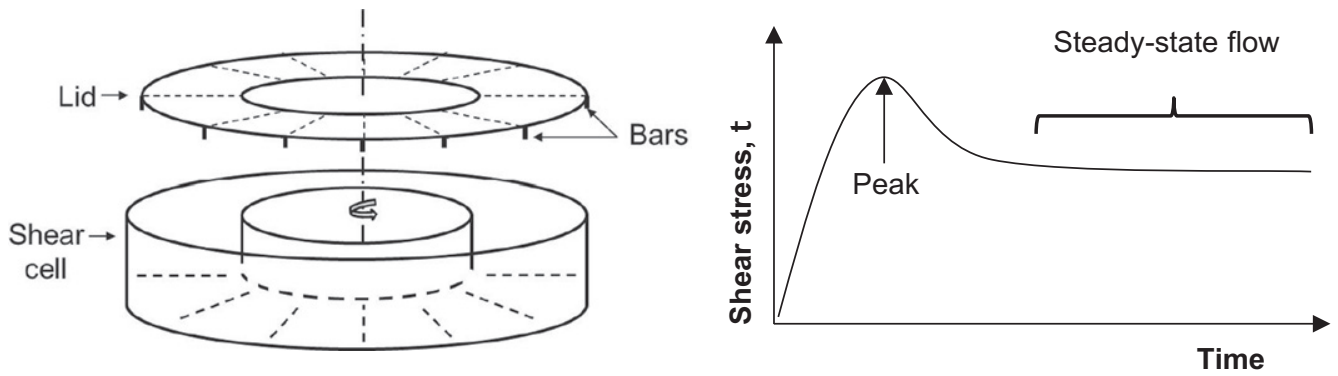

Fig. 3. (Left) Schematic representation of the annular shear cell. (Right) Schematic representation of shear stress-time diagram from the shear test.

the one measured for $70-110 \mu \mathrm{m}$, about 0.42 . Fig. 4 shows the variation of the voidage fraction with the liquid fraction increasing up to $20 \%$. The same variation is observed for the two different sizes of glass beads; at first, a small decrease of the voidage fraction is occurred due to the lubrication in the presence of tiny amounts of liquid. Chou and Hsiau [3] reported that no liquid bridges are formed at very small amount of liquid because the latter is trapped on the surface of particles between asperities. Then, the voidage fraction starts to increase with the liquid content due to the formation of liquid bridges, which are responsible for the cohesive force allowing the granular system to sustain a loose assembly with some gaps in between. Indeed, for small amount of liquid $\left(V_{R}<1 \%\right)$, the liquid bridges are formed at some of the contact areas between particles. Thus, the liquid bridges will bring into contact some of the particles and lead to the formation of gaps in other areas. Furthermore, the surface roughness plays a role in the formation of liquid bridges. For small values of $V_{R}$, the liquid is accumulated around the asperities at the contact area between particles. In this case, the capillary force induced from the liquid bridges depends on the volume of the added liquid $\left(F_{C} \sim \gamma \mathrm{V} / a^{2}\right)$, where $a$ is the local surface roughness height $[6,8]$. When the amount of liquid increases further $\left(1 \%<V_{R}\right)$ the effect of the surface roughness becomes negligible and the capillary force is determined by the radius of the particles $\left(F_{C}=2 \pi \gamma R\right)$. Thus, the capillary force is independent on the volume of the liquid bridge. The saturation of the capillary force for $\left(1 \%<V_{R}<14 \%\right)$ leads to a saturation of the voidage fraction variation observed in Fig. 4. After the liquid bridges are formed in most of the contact points, the increase of the amount of liquid contributes to enlarge the volume of liquid bridge. The voidage fraction starts to decrease since the liquid progressively occupies the space of the air.

The effect of liquid on the voidage fraction is also more pronounced for small particle size. This was observed for other size of glass beads ( $250 \mu \mathrm{m}, 1000 \mu \mathrm{m}, 2000 \mu \mathrm{m}$ and $4000 \mu \mathrm{m}$ ) in the work of Feng \& Yu [5] and Yu et al. [25]. In fact, by decreasing the size of particles, the capillary

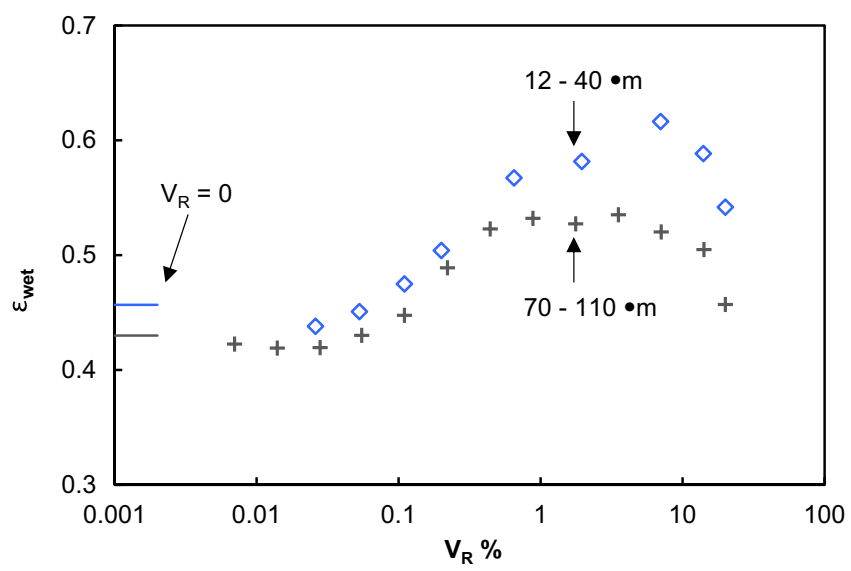

Fig. 4. Variation of the voidage fraction with the liquid fraction for two different sizes of glass beads: diamond for $12-40 \mu \mathrm{m}$, plus for $70-110 \mu \mathrm{m}$. forces become more relevant compared to the gravitational forces and hence the effect on the voidage fraction is more pronounced. A granular bond number $B o$ is calculated in order to compare the capillary and the gravitational effects for the glass beads of $12-40 \mu \mathrm{m}$ and $70-110 \mu \mathrm{m}$. This number is the maximum capillary force relative to the weight of

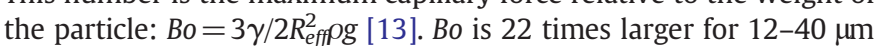
glass beads than for $70-110 \mu \mathrm{m}$ glass beads. This can be explained by the fact that the number of liquid bridges per unit volume is much larger for the small particle size compare to the big size. Consequently, the effect of the capillary force is more pronounced for the small particle size. The effect of adding more liquid amount to the granular media on the voidage fraction will be investigated in the next sections.

\subsubsection{Shear stress of partially wet granular material}

The flow behaviour of the dry glass beads $12-40 \mu \mathrm{m}$ is more cohesive compared to the $70-110 \mu \mathrm{m}$. This can be noticed by looking at the flow behaviour of the two samples of glass beads in a small container of $1000 \mathrm{~cm}^{3}$; a free flowing is observed for the large size versus an avalanching flow for the smaller one. The measurement of the apparent friction coefficient from the shear - normal stresses curves gives 0.44 and 0.4 for small and large sizes respectively. Indeed, the Van-der-Waals forces increase the apparent friction in the dry case for small particles.

Fig. 5-a shows the shear-normal stresses variation with the liquid fraction for $70-110 \mu \mathrm{m}$ glass beads. Generally, we observe an increase of the shear stress by increasing the liquid content up to $20 \%$. At low liquid fraction $\left(V_{R} \leq 0.1 \%\right)$, the shear stress increases linearly with the normal stress. However, by increasing further the quantity of liquid a slope change is observed around $4 \mathrm{kPa}$ of normal stress; at low normal stress $(\sigma \leq 4 \mathrm{kPa})$, the granular behaviour under shearing is frictional where the apparent friction (obtained from the slope of curve) increases with the liquid fraction. However, at high normal stress $(\sigma \geq 4 \mathrm{kPa})$, the granular behaviour is cohesive where the apparent cohesion (obtained by extrapolation of curves at zero normal stress) increases with the liquid fraction and the apparent friction remains constant. These two different regimes are explained by the effect of the normal stress on the configuration of the wet granular material. The granular structure passes from loose to dense by increasing the normal stress and the shear stress response is affected consequently [10].

Fig. 5-b shows the shear-normal stresses variation with the liquid fraction for 12-40 $\mu \mathrm{m}$ glass beads. Generally, we observe a linear variation of the shear-normal stresses for the different liquid fractions. We point out a change of behaviour for high normal stress $(\sigma \geq 8 \mathrm{kPa})$, i.e. data are slightly drifted from linearity toward higher normal stress. This regime cannot be described with an apparent cohesion $(\tau=$ $\mu \sigma+\mathrm{c}$ ) on the contrary to the case of $70-110 \mu \mathrm{m}$ glass beads. The apparent friction coefficient is calculated from the slope of curves, for normal stress up to $8 \mathrm{kPa}$. Data are well fitted by linear regression with a coefficient of determination $\left(R^{2}>0.998\right)$ for all cases. The variation of the apparent friction coefficient with the liquid fraction is given in Fig. 6 . This apparent friction coefficient increases for an increase in the liquid fraction. However, we can distinguish two regimes: for small liquid content $\left(V_{R} \leq 1 \%\right)$, the apparent friction is slightly increased with the liquid 

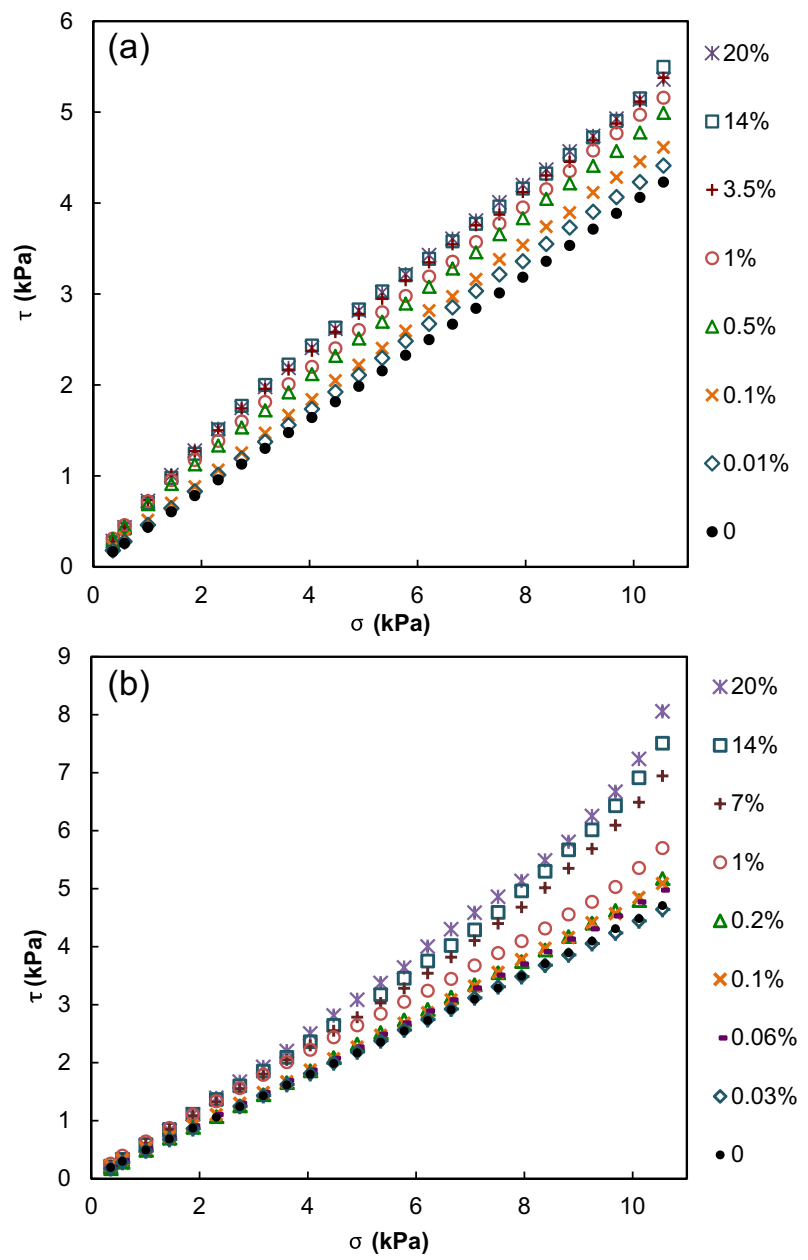

Fig. 5. Shear stress variation with the normal stress wet glass beads with a volume fraction ranging from 0 to $20 \%$. (a) glass beads of 70-110 $\mu \mathrm{m}$ [10] and (b) glass beads of $12-40 \mu \mathrm{m}$.

from 0.44 in the dry case to 0.5 at $1 \%$. The apparent cohesion, which can be obtained by extrapolation of curves at zero normal stress, remains low and close to the dry data as it can be observed from Fig. 5-b. For higher liquid content $\left(V_{R}>1 \%\right)$, the increase of the apparent friction coefficient is more significant, e.g. it rises from about 0.5 at $1 \%$ to 0.65 at

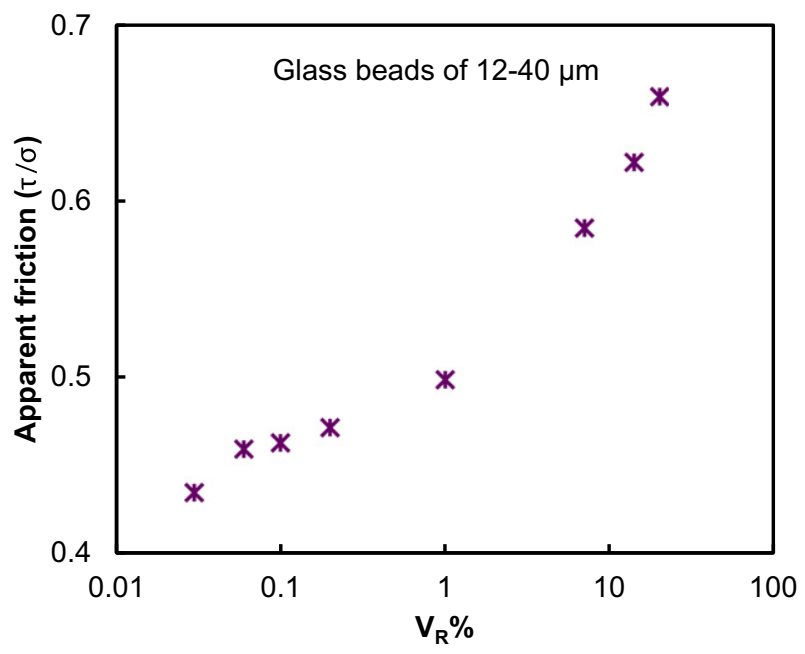

Fig. 6. Variation of the apparent friction coefficient with the liquid fraction of $12-40 \mu \mathrm{m}$ glass beads applied to normal stresses up to $8 \mathrm{kPa}$.
$20 \%$. This regime resembles to the regime observed at low normal stress for $70-110 \mu \mathrm{m}$ : the apparent friction increases with the liquid fraction up to $20 \%$. Moreover, no saturation of the shear stress is yet observed for the small glass beads with the liquid fraction increasing; for liquid fraction up to $20 \%$, the shear stress is still increasing with the liquid fraction unlike the case for $70-110 \mu \mathrm{m}$ glass beads (curves are superimposed in the range of $3.5-20 \%$ of liquid fraction). This may be explained by the fact that for the small beads the number of particles in the shear cell is much larger. An estimation of the number of glass beads in the shear cell shows that the small glass beads are 70 times the number of the big ones. Thus, the number of the coordination number by unit of volume is much larger and hence the number of liquid bridges formed at the contact points increases as well. We assume that the saturation of the shear stress is reached when the number of liquid bridges is completed. Indeed, the shear resistance get rise from the number of liquid bridges broken under shearing. The saturation of the shear stress can not be reached while the number of liquid bridges is increasing with the liquid addition.

\subsubsection{Estimation of the tensile strength}

In the pendular regime, Rumpf [17] proposed a theoretical model to estimate the tensile strength $\mathrm{T}_{\mathrm{S}}$ from the liquid bridge forces, for monosized spheres:

$\mathrm{T}_{\mathrm{S}, \text { pendular }}=(1-\varepsilon) \frac{k}{\pi} \frac{F_{C}}{d^{2}}$,

where $F_{C}$ is the capillary force, $k$ is the coordination number and $\varepsilon$ is the voidage fraction of the wet granular material. To calculate the capillary force, the approach given by Adams \& Perchard [1] is used

$F_{C}=2 \pi R \gamma \sin ^{2} \alpha+\pi R^{2} \sin ^{2} \alpha \Delta P$,

where $R$ is the particle radius, $\alpha$ is the half filling angle and $\Delta P$ is the capillary depression as given by Young Laplace expression. More details about this approach can be found in these references (Adams \& Perchard [1]; [10]).

It was shown in our previous study [10] how the liquid fraction and the packing density affect largely the tensile strength. However, there is another parameter, which is as important in the estimation of the tensile strength: the particle size. It is reported in the literature that fine particles have higher strength than large particles [11]. However, we have seen that both the liquid saturation and the packing density are also affected by the particle size decrease. In this section, the tensile strength of $12-40 \mu \mathrm{m}$ glass beads is estimated from the model of Rumpf and compared to the results of $70-110 \mu \mathrm{m}$ glass beads. Although the size of particles is smaller, the size of the asperities observed by AFM is very close to the one observed for $70-110 \mu \mathrm{m}$. An approximate value of the dimensionless half-separation distance of about 0.06 is considered for the small size glass beads and about 0.025 for the large size glass beads. We recall that this value step in the calculation of the main radii of the liquid bridge curvature necessary to compute the capillary force and then the tensile strength [10]. The capillary force increases with the particle size increasing, however the tensile strength is inversely proportional to the particle size.

Fig. 7 shows the calculated tensile strength $T_{S}$ as a function of the volume ratio $V_{\mathrm{R}}(\%)$ for various potential coordination numbers $k$ (continuous lines). We clarify that the irregularities of the theoretical curves (continuous lines) are caused by the values of the voidage fraction used in Eq. (1), which correspond to the experimental values measured for different liquid fractions. On one hand, as expected, the observed values of $T_{S}$ are higher than the one observed for $70-110 \mu \mathrm{m}$ glass beads. This can be explained by the fact that the number of contact per unit of surface increases for a decrease in the particle size [2] and consequently the number of liquid bridges increases too. Therefore, higher tensile forces are required to produce rupture of the liquid bridges in the shearing 

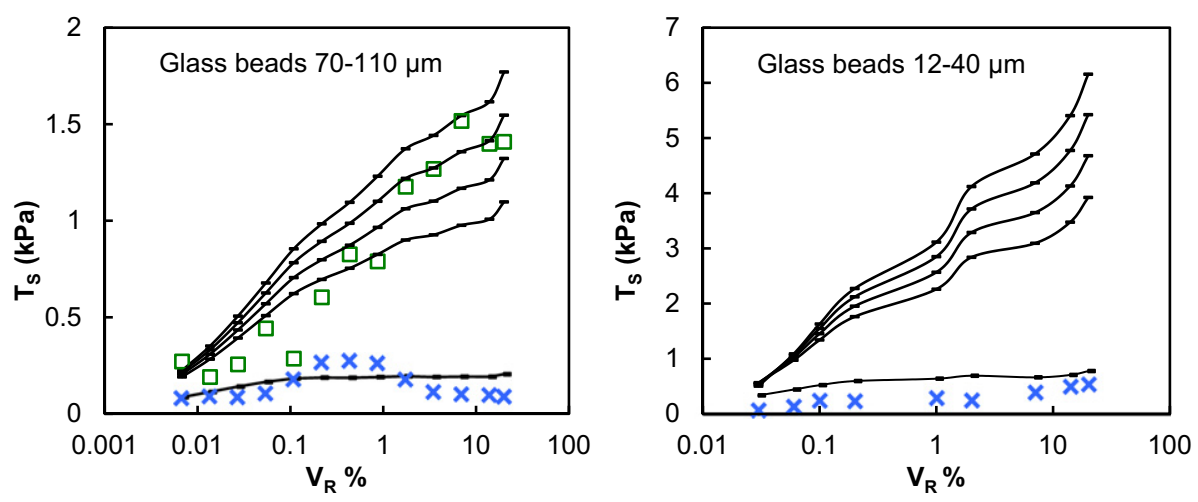

Fig. 7. Comparison between experimental (crosses and squares) and theoretical tensile strength (continuous lines) variation with the liquid fraction. The theoretical data are obtained from Eq. (4) for different values of the coordination numbers $(1,5,6,7$ and 8 , displayed from bottom to top). The experimental data are represented by crosses for low normal stress ( $\sigma<4 \mathrm{kPa})$ and squares for high normal stress $(\sigma>4 \mathrm{kPa})$. Left, for glass beads $70-110 \mu \mathrm{m}$ and right, for glass beads of $12-40 \mu \mathrm{m}$.

plane. On the other hand, the experimental data (crosses) has value whose magnitude corresponds to a low number of capillary bridges broken. In fact, it was observed that the small glass beads have looser packing density compared to the bigger glass beads (see Fig. 4). Therefore, higher normal stresses (beyond $11 \mathrm{kPa}$ ) are needed to reach denser packing density and hence higher tensile strength, which should correspond to the upper continuous lines in (Fig. 7). This may also explain the profile of shear stress-normal stress curves of small glass beads (Fig. 5b), which resembles to the profile of curves at low normal stress $(\sigma<4 \mathrm{kPa}$ ) of big glass beads (Fig. 5 -a); we assume that a slope variation can be obtained at higher normal stress (beyond $11 \mathrm{kPa}$ ).

\subsection{Effect of the liquid content}

In the pendular state, where the liquid bridges are mainly formed at the contact point between particles, it was shown that the cohesive force acts through the liquid bridges (see Fig. 8). The shear resistance increase due to the rupture of liquid bridges under shearing. The redistribution of liquid in the granular material, after the contact has been established between particles, affects the bridge volume and hence the critical distance at which the liquid bridges breakdown $[7,9]$. Herminghaus investigates the effect of the separation distance on the required energy to break the liquid bridge. He reported that the energy change $\left(\Delta E_{C}\right)$ is approximately equivalent to $\left(\Delta E_{C} \sim S_{d}^{3 / 2}\right)$, where $S_{d}$ is the separation distance [7]. Therefore, the increase of the liquid fraction contributes to enhance the shear resistance of the granular material through the distribution of liquid between contact points.

In the funicular state, some of the gaps are filled with liquid; the cohesion acts through the suction at the liquid-air interface together with the remained liquid bridges. In the capillary state, almost all the gaps are filled with the liquid; the cohesion is only ensured by the suction at the liquid-air interface. Therefore, the texture of the granular material changes depending on the quantity of liquid. We expect also that the mechanical behaviour of the granular material for the different states changes. In this section, the effect of liquid of different saturation states is investigated. The glass beads of $70-110 \mu \mathrm{m}$ are considered here and the liquid fraction is extended to up to $60 \%$. The variation of the voidage fraction, as shown in Fig. 4, will be discussed for more liquid fractions. Moreover, the voidage fraction will also be analysed from X-ray tomography images. The mechanical properties of the different states of saturation will be analysed from the shear stress measurement.

\subsubsection{Observations of the wet granular bed}

The effect of liquid on the voidage fraction is now investigated for different saturation states of liquid, i.e. pendular, funicular and capillary states. Data in Fig. 4 are extended to more liquid fractions up to $60 \%$. The latter is close to the maximum liquid fraction that can be held by the granular material before reaching the slurry state. It can be estimated from this relationship $\left(\mathrm{V}_{\mathrm{R}} \approx \varepsilon /(1-\varepsilon)\right)$ that the slurry state is reached at almost $70 \%$ of liquid fraction, for a voidage fraction of $(\varepsilon=0.41)$. For large liquid fractions, beyond the pendular regime, the capillary force arises from the suction at the air-liquid interface. Yu et al. [25] reported that, after a critical value of the liquid fraction, the voidage fraction might decrease. It is assumed that the capillary forces vanish beyond that maximum value [19]. Fig. 9 shows that $\varepsilon_{\text {wet }}$ is decreasing linearly for an increase of the liquid fraction from $20 \%$ to $60 \%$. The linearity of data is observed at low and high normal stresses applied upon the wet granular bed during measuring of the voidage fraction. This indicates that the granular material skeleton is invariable and the addition of liquid simply fills the space between beads without much affecting the structure of the granular bed. In order to gain a qualitative understanding of the voidage fraction variation at a mesoscopic scale in the presence of a wetting liquid, an X-ray tomography was carried out and the analysis will be discussed in the following.

3.2.1.1. X-ray tomography. The X-ray tomography is a potential technique to analyse the structure of the granular material and the liquid distribution [18]. In this work, this technique is used to qualitatively
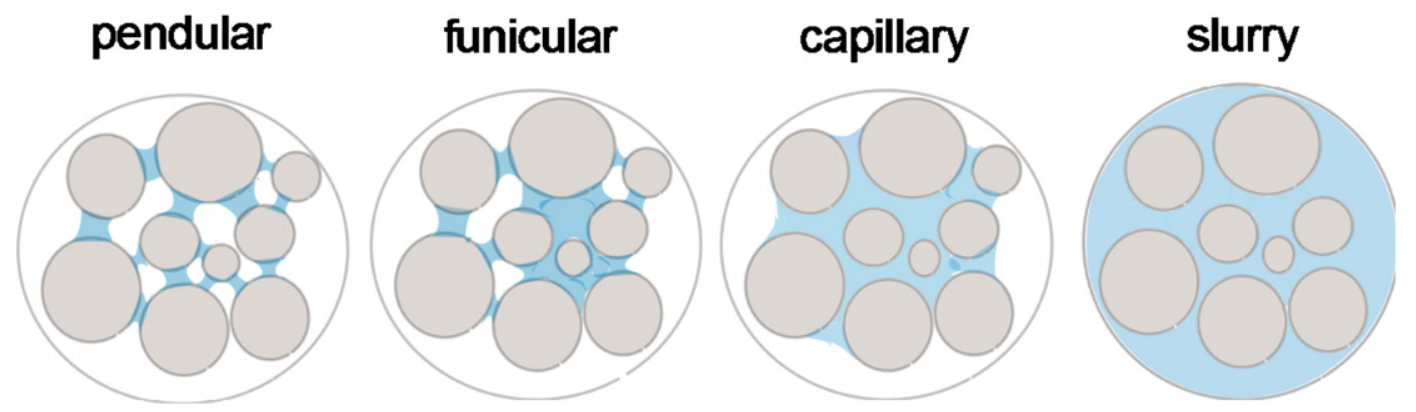

Fig. 8. Different states of saturation of liquid in the granular materials. 


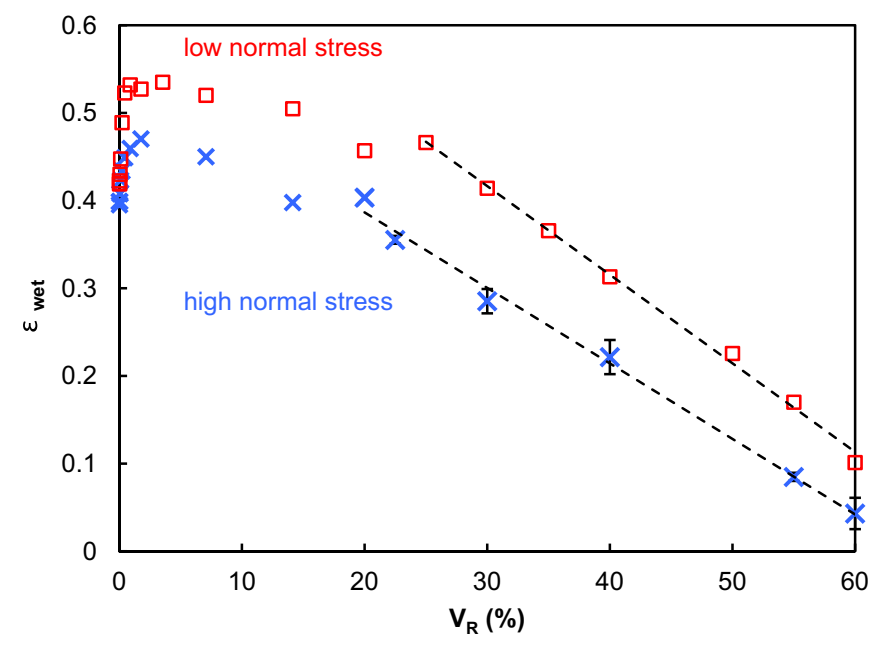

Fig. 9. Variation of the voidage fraction $\left(\varepsilon_{\text {wet }}\right)$ as a function of the liquid fraction.

analyse the mean voidage fraction in the glass beads bed depending on the amount of liquid and to identify the existence of agglomerates at large amount of liquid.

Fig. 11-left shows 2D cross-sectional images of four samples of wet glass beads with different liquid fractions (0, 0.5\%, 3.5\% and 40\%). These samples have been chosen because they have shown different voidage fraction values (see Fig. 9). From these images we will try to analyse the distribution of the voids in the granular assembly and its dependency on the liquid fraction. The bright areas correspond to the glass beads, the dark areas to the voids and the areas with intermediate intensities of grey to the liquid. It is not obvious to distinguish the three phases in the raw images (on the left). In order to do so, the histograms of the frequency of grey intensities are determined for each sample (see Fig. 10). The three phases are clearly distinguished in the histogram of $40 \%$ of liquid fraction, i.e. three separated peaks are observed, and this is because the amount of liquid is large enough to give a peak. However, for the sample of $0.5 \%$ and $3.5 \%$ no peak was detected for the liquid phase due to the small amount of liquid. Yet, if we zoom in the raw images we can see other shades of grey around the bright areas (glass beads), which most likely correspond to the liquid phase. It can be observed in the histogram a large space between the two peaks, which most likely corresponds to the liquid phase. For the dry sample, one clear peak is observed for the glass beads and another small peak for the air phase.

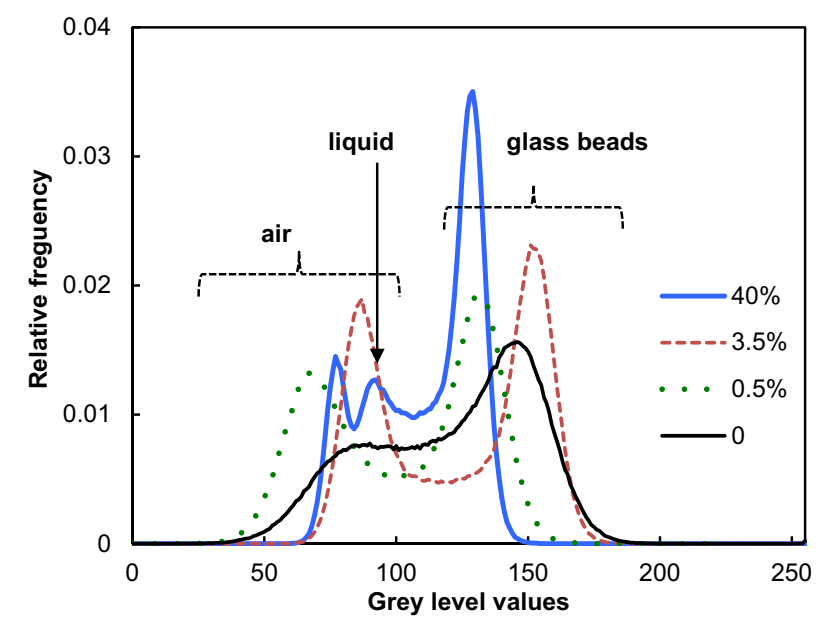

Fig. 10. Histograms of the frequency-intensity of grey levels from the raw images. Each peak is attributed to one phase of the wet granular material (glass beads, liquid or air).
In order to analyse these images, a unique colour is attributed to each phase, i.e. white for the glass beads, black for the air and blue for the liquid. The liquid fraction (volume of liquid / volume of glass beads) was checked out for the image of $40 \%$ by counting the number of pixels (number of blue pixels / number of white pixels). The liquid fraction calculated is well estimated from the image analysis, about $40 \pm 2 \%$. This means also that the liquid is evenly distributed in the granular material for high liquid content at least. For low liquid contents $(0.5 \%$ and $3.5 \%)$, the peak of the liquid phase is not observed. Therefore the range of grey intensity values, which corresponds to the liquid, is defined such that the liquid fraction is conserved. The treated images are given in Fig. 11, on the right hand side, next to the corresponding raw images.

The observation of the treated images shows that the voidage fraction (black pixels) increases with the liquid content. The dry case gives the densest configuration of the granular material since the particles are not cohesive. The observed voids are also evenly distributed in the dry granular material. By adding small amount of liquid $\left(\mathrm{V}_{\mathrm{R}}=\right.$ $0.5 \%$ ), small gaps of two or three times the size of the beads are formed and uniformly distributed. Further increase of the amount of liquid to $3.5 \%$ leads to increase the size of the gaps. The blue areas are observed at some contact points for the image of $3.5 \%$ but not that clear since the amount of liquid is yet small. However, it is clearly observed for $40 \%$ that the liquid exists at the contact areas and also occupies the spaces in between some grains. Large agglomerates coexist with large gaps. The gaps and agglomerates have different sizes and seem to be not uniformly distributed in the granular assembly. Smaller agglomerates are formed at lower amount of liquid. As the liquid fraction increases, the small agglomerates merge into larger ones [18].

We also estimate the voidage fraction from the image analysis. Thus, different images for each sample have been used in order to calculate an average value of the voidage fraction. The images were chosen in a way that they represent different zones of the sample from the bottom to the top of the capsule (see about the preparation of sample in Materials and methods section). For each image, 16 zones have been selected to measure the voidage fraction in order to analyse the distribution of the void depending on the liquid fraction. The selected zones are represented as squares of about $1 \mathrm{~mm}$ of side, which is equivalent to about 12 glass beads side by side. The voidage fraction in each zone is calculated by counting the number of pixels, the black pixels (volume of void) divided by the number of black, white and blue pixels (total volume) gives $\varepsilon_{\text {wet }}$ as expressed in Eq. (1). The variation of the calculated voidage fraction is in agreement with the variation observed in Fig. 9, i.e. the voidage fraction increases with small liquid fraction $(0.5 \%$ and $3.5 \%)$ comparing to the dry case and decreases when the liquid content increases to $40 \%$ (see Table. 2). In order to analyse the distribution of the void depending on the liquid, a relative standard deviation (RSD) is calculated. The RSD is the standard deviation of the values of the voidage fraction of the different selected zones divided by the mean value. We conclude from the values of RSD that the voids are evenly distributed in the dry case and at small liquid fractions (the RSD is about $5 \%$ ). However, as expected, the increase of the amount of liquid leads to a non-uniformity of the voids in the granular bed (the RSD is about 15\%). We conclude that, on the contrary to what was assumed before, large amount of liquid changes the structure of the granular material and not just fills the empty spaces. The liquid at $40 \%$ leads to the rearrangement of the glass beads by forming agglomerates and hence forming new gaps in between (see Fig. 12). Both gaps and agglomerates have different size distributions.

\subsubsection{Investigation of the shear stress at large liquid content}

In this section, the effect of liquid on the shear behaviour of the glass beads of $70-110 \mu \mathrm{m}$ is studied for different saturation states of liquid. The shear stress response of the wet glass beads is calculated in the same manner as previously. We are still focusing on the shear stress at steady-state but we choose to present the data using a stress ratio. The latter is the shear stress divided by the corresponding normal stress. 
dry

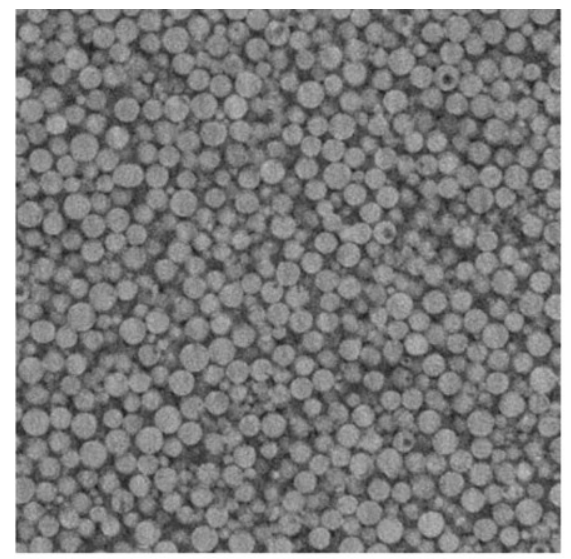

$0.5 \%$

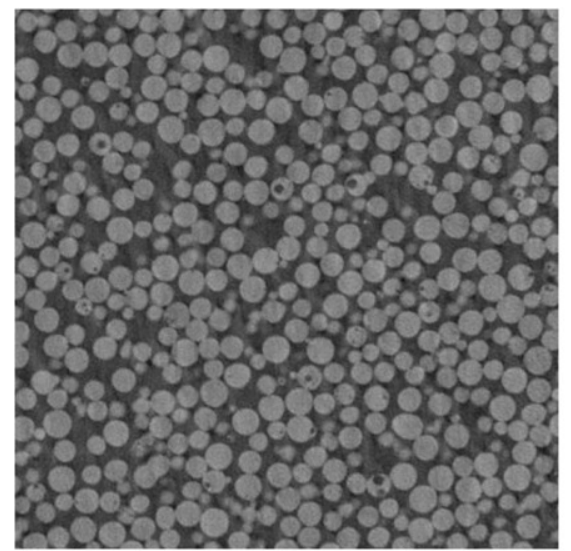

$3.5 \%$

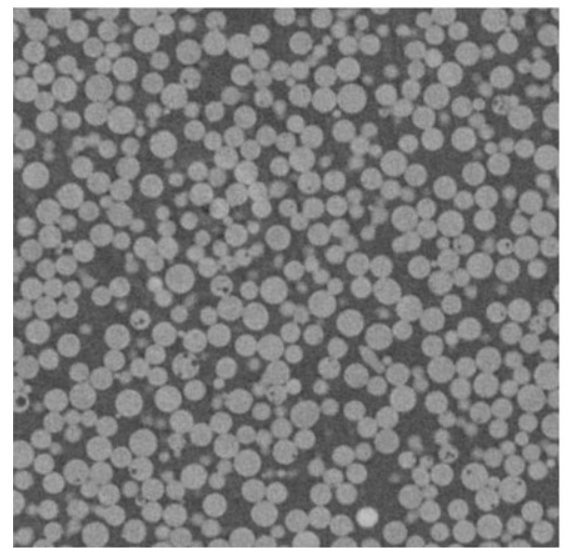

$40 \%$

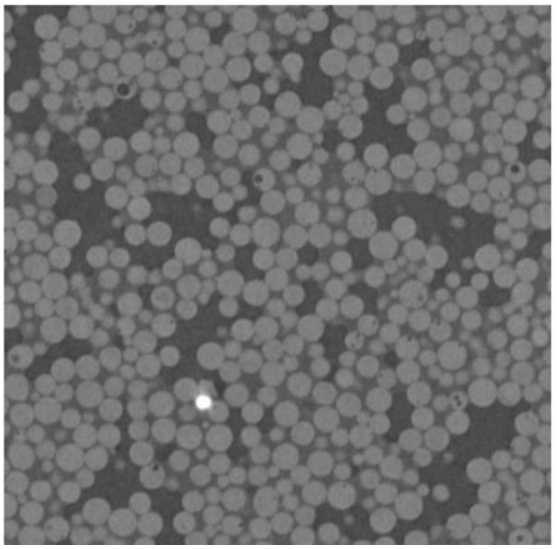

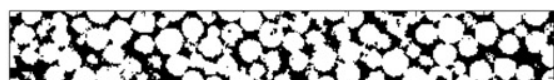
$3 x+20300$

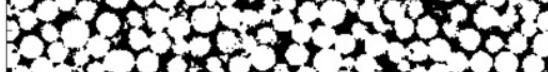
tor

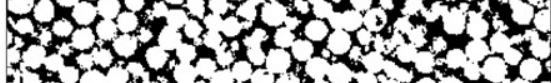

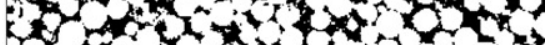
$-5 x+2,20$

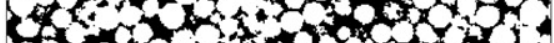

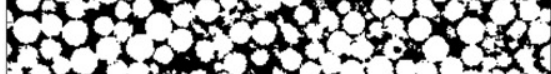
Det $x+x+x+x+3$ $6,34 \times 2+15,50$
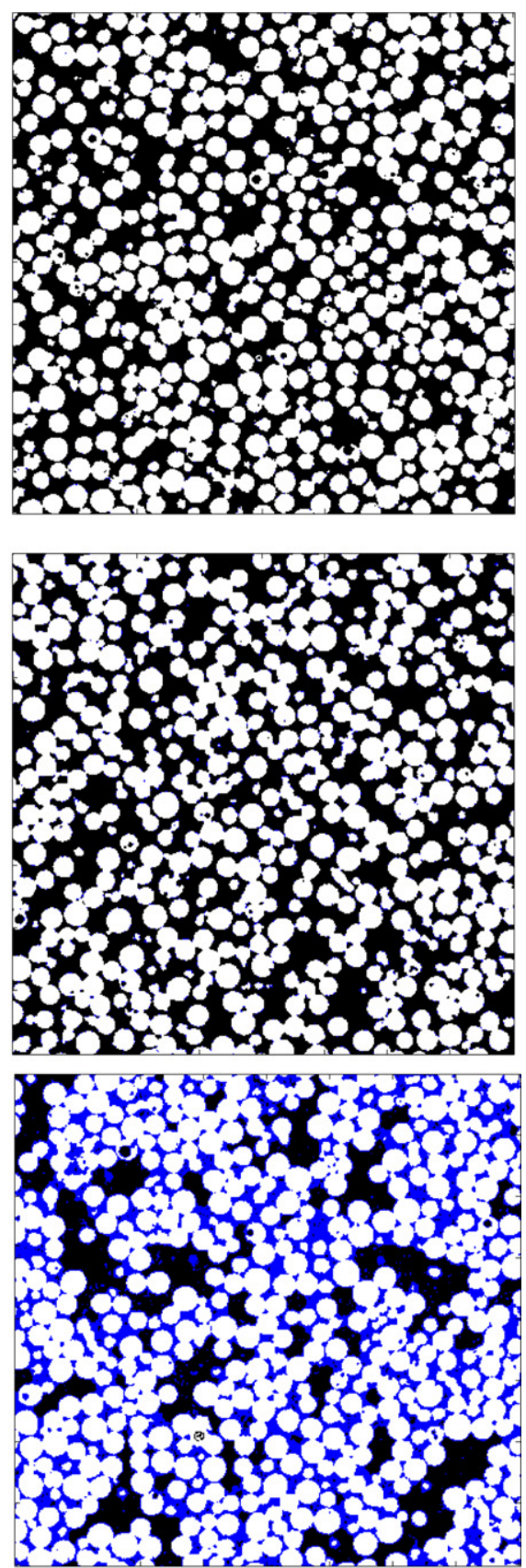

Fig. 11. 2-D cross sectional images of wet glass beads of $70-110 \mu \mathrm{m}$ with different liquid fractions $(0,0.5 \%, 3.5 \%$ and $40 \%$, from the top to the bottom, respectively). On the left, the raw images and, on the right, the treated images. The latter allow distinguishing the three phases, i.e. black: air, white: glass beads, blue: liquid. 
The presentation of the data in this manner helps to illustrate better the contribution of the capillary force on the shear stress. Also, it allows distinguishing different regimes of the stress ratio variation depending on the liquid fractions as you can see in Fig. 13. We can distinguish four regimes:

a) For liquid fraction varying between $0.01 \%$ and $20 \%$ an overview of all the data shows that the stress ratio increases with the liquid fraction and decreases by increasing the normal stress. A critical stress ratio value is observed at high normal stress, i.e. the stress ratio becomes independent on the normal stress. Depending on the amount of liquid, this constant value is obtained at different normal stress values. Indeed, the value of the critical normal stress (value from which the stress ratio becomes constant) increases with the liquid fraction. This assumes that the effect of the capillary force is more pronounced at low normal stresses applied to the granular material comparing to the frictional force. Also, the effect of the amount of liquid is more relevant at low normal stresses than at high normal stresses.

b) For liquid fraction varying between 25\% and 40\%: the stress ratio is almost independent on the normal stress. An increase of the stress ratio is observed from $25 \%$ to $30 \%$ of liquid fraction, however no variation is observed between $30 \%$ and $40 \%$ where data are superimposed. The X-ray tomography for $40 \%$ shows that the regime corresponds to the funicular state of saturation where the glass beads form agglomerates with different gaps in between.

c) For liquid fraction varying between $\mathbf{5 0 \%}$ and $\mathbf{5 5 \%}$ : the stress ratio variation resembles to the one observed in regime $a$ ). In comparison with the variation in regime $b$ ), the stress ratio values increase at low normal stress but decrease at high normal stress. This means that by applying high normal stress to the wet glass beads, we reduce the voidage fraction and hence we get closer to the capillary regime where the capillary force decreases. The observation of the voidage fraction for $55 \%$ at high normal stress shows that the void only presents $10 \%$ of the total volume of the granular material (see Fig. 9).

d) For liquid fraction of 60\%: the stress ratio decreases for an increase of the normal stress. At high normal stress, the stress ratio joins the value obtained for the dry case. This means that the capillary regime is reached and overcame at high normal stresses since the stress ratio get back to the dry one, i.e. the gaps are totally filled by liquid and the capillary force vanished. Indeed the suction at the interface air-liquid is equal to zero when the particles are fully immersed.

Fig. 14 shows the variation of the mean value of the stress ratio calculated at high normal stress between $8 \mathrm{kPa}$ and $11 \mathrm{kPa}$ as a function of the liquid fraction in the range of $0.01 \%$ to $60 \%$. The shear stress evolution of the wet glass beads can be analysed from this graph. First, an increase of the shear stress with the liquid is observed until saturation is reached. The stress ratio goes up from 0.4 to 0.5 just by adding $1 \%$ of liquid. After saturation, the shear stress increases again from about 0.5 to 0.6 when the liquid fraction goes from $20 \%$ to $40 \%$. At around $40 \%$, the maximum shear stress is observed and after that any increase of liquid leads to decrease the stress.

\subsubsection{Estimation of the tensile strength}

In this section, we investigate the tensile strength in the funicular and capillary states of saturation. The model of Rumpf is only valid for the pendular state, where the capillary force is estimated from the liquid bridges distributed across the surface of rupture of the agglomerate. In the capillary state, the liquid fills all the space between particles and the force to hold the particles together is only produced from the capillary pressure, $P_{c}$, at the agglomerate surface. The tensile strength is given by Schubert [15] as:

$\mathrm{T}_{\mathrm{S}, \text { capillary }}=S P_{c}$
Table 2

Values of the voidage fraction $\varepsilon_{\text {wet }}$ and the RSD for each liquid fraction.

\begin{tabular}{lllll}
\hline Liquid fraction & 0 & $0.5 \%$ & $3.5 \%$ & $40 \%$ \\
\hline Average $\varepsilon_{\text {wet }}$ & 0.31 & 0.46 & 0.45 & 0.15 \\
RSD & $5 \%$ & $5.2 \%$ & $3 \%$ & $15 \%$ \\
\hline
\end{tabular}

where $P_{c}$ is the capillary pressure and is given as:

$P_{c}=a^{\prime} \frac{1-\varepsilon}{\varepsilon} \frac{\gamma}{d}$

where $a^{\prime}$ is a dimensionless factor ranging between 6 and 8 , which is dependent on the particles rearrangement.

Using the assumption to estimate the coordination number, $k$, from the voidage fraction as $k=\pi / \varepsilon$ [16], Eq. (7) can be written as:

$P_{c}=a^{\prime} \frac{1-\varepsilon}{\pi} k \frac{\gamma}{d}$

$S$ is the liquid saturation, which is defined as the volume of liquid divided by the volume of void in the granular material and expressed as:

$S=\frac{1-\varepsilon}{\varepsilon} \mathrm{V}_{\mathrm{R}}$

In the funicular state, the tensile strength is estimated from those obtained in the pendular state and the capillary state. Indeed, zones with liquid bridges and zones completely saturated with liquid coexist in the funicular regime [15]. Therefore, the capillary force arises from the liquid bridge forces and the capillary pressure. The tensile strength in the funicular regime is expressed as:

$\mathrm{T}_{\mathrm{S}, \text { funicular }}=\mathrm{T}_{\mathrm{S}, \text { capillary }} \frac{S_{2}-S}{S_{2}-S_{1}}+\mathrm{T}_{\mathrm{S}, \text { pendular }} \frac{S-S_{1}}{S_{2}-S_{1}}$,

where $S_{1}$ is the limit saturation between the pendular and the funicular states and $S_{2}$ is the limit saturation between the funicular and the capillary states. Two approximate values of $S_{1}$ and $S_{2}$ are considered as 0.25 and 0.9 respectively, from the literature [15].

It has been reported that the cohesive force due to the addition of liquid rises in the pendular, funicular and capillary states. This cohesion leads to a finite tensile strength in quasi-static experiments [12]. Fig. 15 shows the theoretical data (continuous lines) and experimental data (crosses or squares) of the tensile strength for wide range of the liquid fraction up to $60 \%$. The experimental tensile strength values are obtained by linear extrapolation of curves in Fig. 5 -a $\left[\tau=\mu\left(\sigma+\mathrm{T}_{\mathrm{S}}\right)\right]$, distinctly at low normal stress $(\sigma \leq 4 \mathrm{kPa})$ and high normal stress $(\sigma \geq 4 \mathrm{kPa})$. The tensile strength, at high normal stress (squares), increases for an increase of the liquid fraction while it remains small at low normal stress (crosses). We observe a good agreement between the experimental and theoretical data. The slope of the curves at high normal stress changes significantly at the boundary between the pendular and the funicular states; we observe a significant increase of the tensile strength in the funicular state compared to the pendular state. Mitarai and Nori have reported that the tensile strength may either increase or decrease with the liquid fraction in the funicular state of saturation. We distinguish an increase of the tensile strength at high normal stress since the capillary forces rise from the pendular to the funicular regime. On the contrary, the tensile strength remains low and perhaps decreases at low normal stress as a result of the size enlargement of gaps and agglomerates in the granular bed. The rolling rearrangement of the agglomerates under traction leads to the breakage of less than one liquid bridge per grains and consequently to reduce the tensile strength value.

Regarding the capillary state, it seems from the estimation of the saturation level (see Eq. (9)) that it is not reached yet. For the maximum 


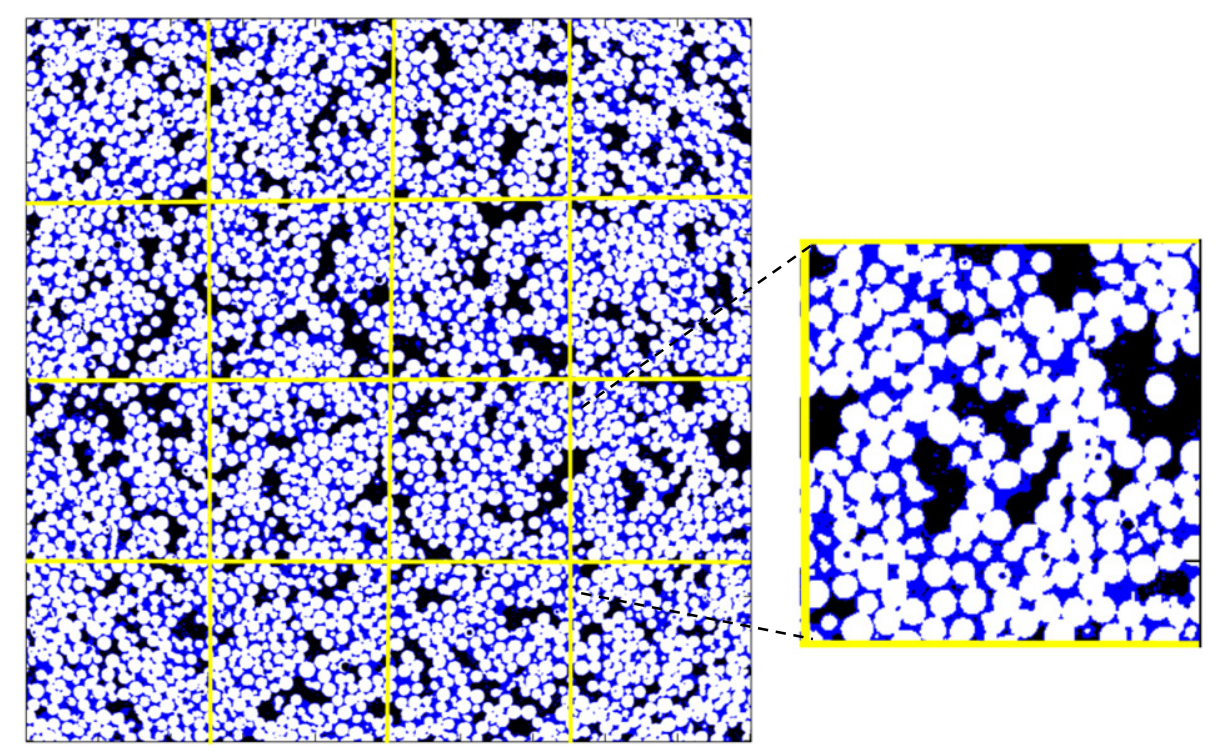

Fig. 12. An example of the cut image to define the different zones to estimate the voidage fraction. The selected squares (zones) are about $1 \mathrm{~mm}$, which is equivalent to 12 particles side by side.

liquid fraction $V_{R}=60 \%$, we calculate a saturation level $S=82 \%$. Pierrat and Caram have reported that the capillary regime occurs at a saturation level $>90 \%$. We assume that the value of the tensile strength may increase further until reaching the capillary state and then decreases. However, it can be observe a decrease of the experimental tensile strength at high normal stress at $60 \%$. The latter highlight the effect of the normal stress in changing the regime. By applying large normal stress the packing density of the wet glass beads decreases and consequently the capillary regime can be reached for smaller liquid content.

\section{Conclusions}

We analysed the effect of particle size on the shear behaviour of partially wet glass beads. It was observed that the saturation level depends on the particle size. The voidage fraction of wet glass beads increases for a decrease in the particle size and the shear stress response to the applied normal stress can be different. We have shown also that the tensile strength increases for the smaller particle size because of the increase in the contact number and the liquid bridges broken in the shearing plane. However, the lower packing density of the small glass beads leads to a
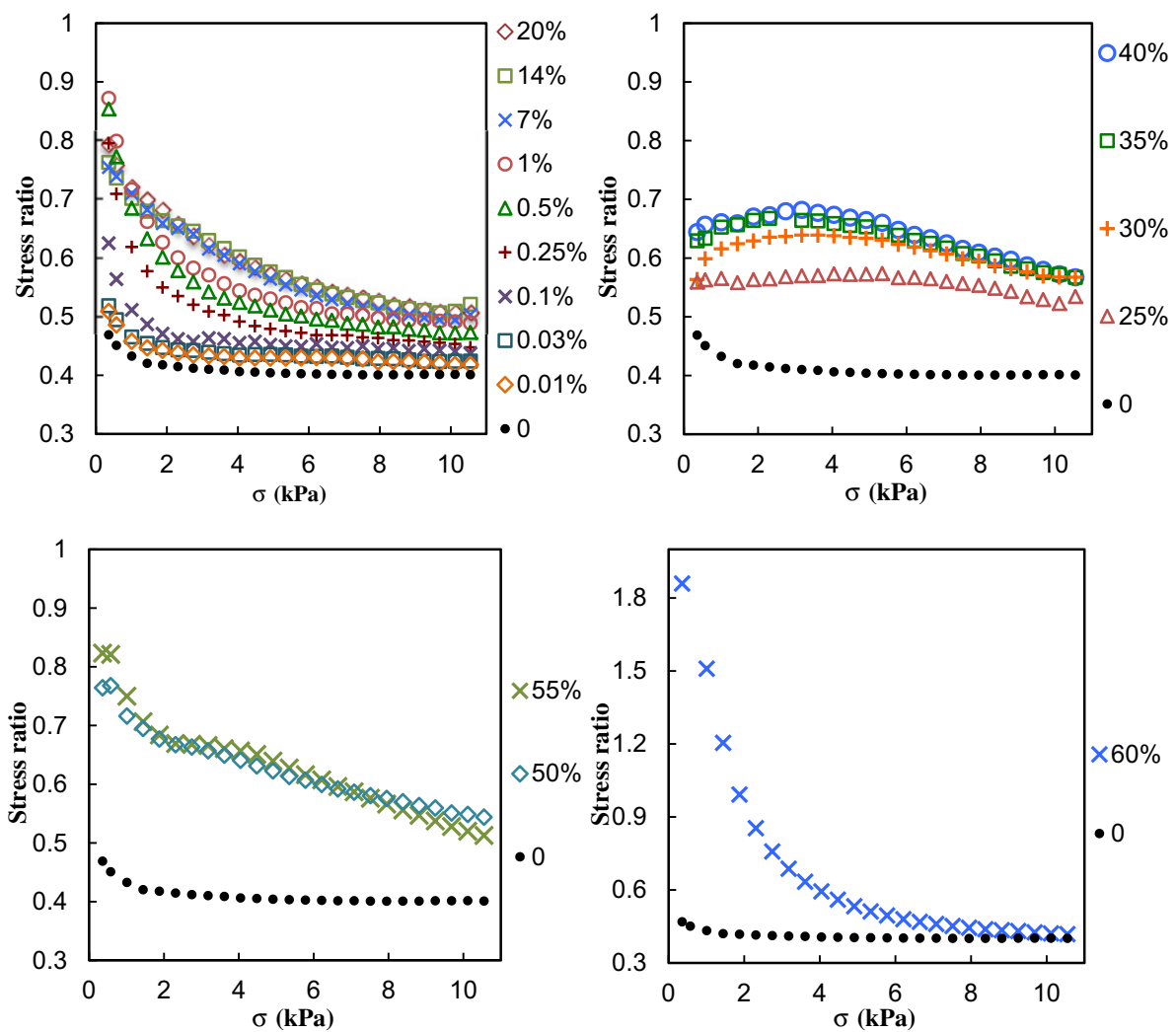

Fig. 13. The stress ratio (shear stress/normal stress) variation with the normal stress of different regimes depending on the liquid fraction. 


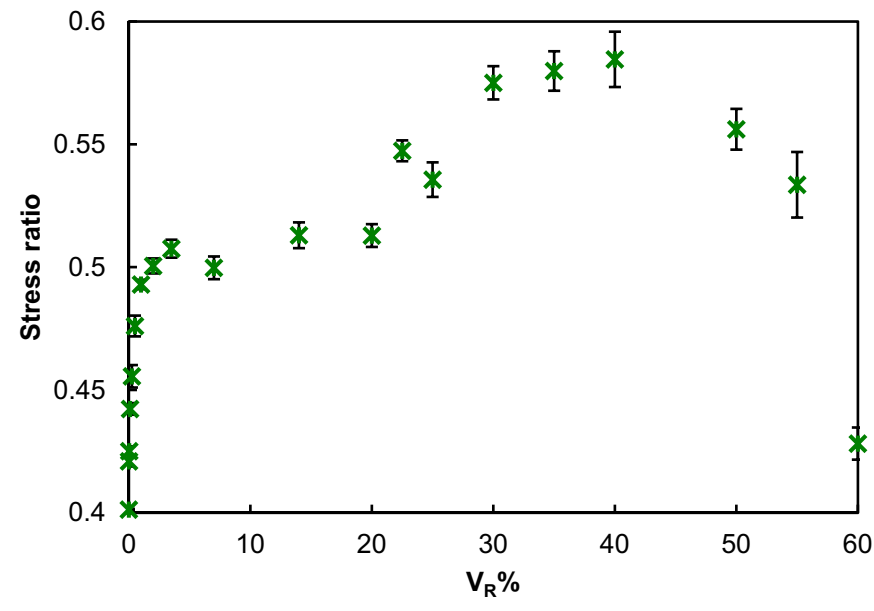

Fig. 14. Variation of the average stress ratio for normal stress (between 8 and $11 \mathrm{kPa}$ ) with the liquid fraction.

lower tensile strength values estimated experimentally. We also investigate the effect of more liquid fractions on the shear behaviour of glass beads of $70-110 \mu \mathrm{m}$. The shear stress increases with the liquid up to a critical value and then decreases. The capillary force contribution on the shear stress vanishes at the capillary state of saturation. Regarding the voidage fraction, a linear decrease is observed for liquid fraction in the range of $20 \%$ to $60 \%$. The tomography analysis showed that the increase of liquid beyond the pendular state leads to the formation of agglomerates. This study highlights the fact that the change of some properties of the granular material can largely change the obtained results, such the particle size studied in this work. Thus we encourage more comparative studies using other materials (solid and/or liquid).

List of symbols

A Area of the lid of the annular shear cell $\left(\mathrm{m}^{2}\right)$

a Local surface roughness height $(\mu \mathrm{m})$

$a^{\prime} \quad$ Dimensionless factor of the particle rearrangement

c Cohesion $\left(\mathrm{N} / \mathrm{m}^{2}\right)$

$d \quad$ Diameter of particle $(\mathrm{m})$

$E_{C} \quad$ Energy required to break a liquid bridge $\left(\mathrm{kg} \cdot \mathrm{m}^{2} \cdot \mathrm{s}^{-2}\right)$

$\mathrm{F}_{1}, \mathrm{~F}_{2} \quad$ Tangential forces applied to the lid $(\mathrm{N})$

$F_{C} \quad$ Capillary force $(\mathrm{N})$

g Gravitational constant $(\mathrm{N} / \mathrm{kg})$

$h \quad$ Height of the bars in the shear cell $(\mathrm{m})$

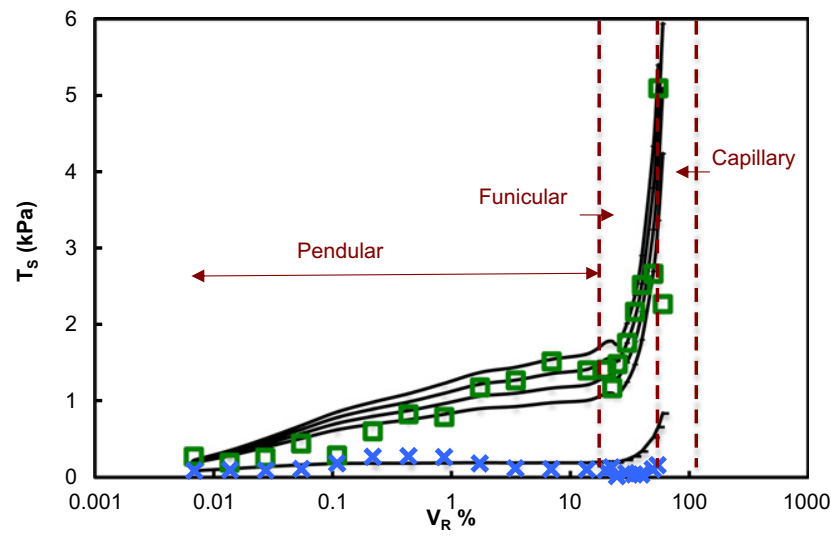

Fig. 15. Experimental and theoretical tensile strength as a function of the liquid fraction on a semi-logarithmic scale. Squares and crosses: experimental data for high normal stress $(\sigma>4 \mathrm{kPa})$ and low normal stress $(\sigma<4 \mathrm{kPa})$ respectively. Continuous lines: theoretical traction for different coordination numbers $(1,5,6,7$ and 8$)$ shown from bottom to top in this figure. $k \quad$ Coordination number

$l \quad$ Distance from the axis of rotation of the shear cell to the force sensors $(\mathrm{m})$

$M \quad$ Normal load ( $\mathrm{kg})$

PEG 400 Polyethylene glycol 400

$P_{c} \quad$ Capillary pressure $\left(\mathrm{N} / \mathrm{m}^{2}\right)$

$R \quad$ Radius of particle (m)

$R_{e} \quad$ External radius of the shear cell (m)

$R_{i} \quad$ Internal radius of the shear cell (m)

$S \quad$ Liquid saturation (\%)

$S_{1} \quad$ Limit saturation between the pendular and the funicular states (\%)

$\mathrm{S}_{2} \quad$ Limit saturation between the funicular and the capillary states (\%)

$S_{d} \quad$ Separation distance between two particles ( $\mathrm{m}$ )

$\mathrm{T}_{\mathrm{S}} \quad$ Tensile strength $(\mathrm{Pa})$

$\mathrm{T}_{\mathrm{S} \text {,pendular }}$ Tensile strength for the pendular regime ( $\mathrm{Pa}$ )

$\mathrm{T}_{\mathrm{S}, \text { funicular }}$ Tensile strength for the funicular regime $(\mathrm{Pa})$

$\mathrm{T}_{\mathrm{S} \text {,capillary }}$ Tensile strength for the capillary regime ( $\left.\mathrm{Pa}\right)$

$v_{p, p} \quad$ Relative velocity particle-particle $\left(\mathrm{m} \cdot \mathrm{s}^{-1}\right)$

$\mathrm{V} \quad$ Liquid bridge volume $\left(\mathrm{m}^{3}\right)$

$V_{R} \quad$ Volume fraction (\%)

\section{Greek symbols}

$\alpha \quad$ Half filling angle $\left({ }^{\circ}\right)$

$\gamma \quad$ Surface tension $(\mathrm{N} / \mathrm{m})$

$\triangle P \quad$ Capillary depression

$\varepsilon \quad$ Voidage fraction

$\varepsilon_{\text {wet }} \quad$ Wet voidage fraction

$\mu \quad$ Friction coefficient

$\mu_{\mathrm{g}} \quad$ Dynamic viscosity of ambient gas $\left(\mathrm{kg} \cdot \mathrm{m}^{-1} \cdot \mathrm{s}^{-1}\right)$

$\mu_{1} \quad$ Dynamic viscosity of liquid $\left(\mathrm{kg} \cdot \mathrm{m}^{-1} \cdot \mathrm{s}^{-1}\right)$

$\rho \quad$ Apparent density $\left(\mathrm{kg} / \mathrm{m}^{3}\right)$

$\rho_{g} \quad$ Density of the ambient gas $\left(\mathrm{kg} / \mathrm{m}^{3}\right)$

$\rho_{L} \quad$ Liquid density $\left(\mathrm{kg} / \mathrm{m}^{3}\right)$

$\rho_{p} \quad$ Density of the particles $\left(\mathrm{kg} / \mathrm{m}^{3}\right)$

$\rho_{S} \quad$ True density $\left(\mathrm{kg} / \mathrm{m}^{3}\right)$

$\sigma \quad$ Normal stress (Pa)

$\tau \quad$ Tangential stress $(\mathrm{Pa})$

$\omega \quad$ Shear cell velocity ( $\mathrm{mrad} / \mathrm{s})$

\section{Acknowledgements}

The authors are thankful for the technical support by C. Rolland, L. Haurie and L. Devriendt.

\section{References}

[1] M. Adams, V. Perchard, The cohesive forces between particles with interstitial liquid, Inst. Chem. Eng. Symp. 91 (1985) 147-160.

[2] J.F. Carr, Tensile strength of granular materials, Nature 213 (5081) (1967) $1158-1159$.

[3] S.H. Chou, S.S. Hsiau, Experimental analysis of the dynamic properties of wet granular matter in a rotating drum, Powder Technol. 214 (2011) 491-499.

[4] A.R. Dexter, D.W. Tanner, Packing densities of mixtures of spheres with log-normal distributions, Nature 238 (1972) 31-32.

[5] C.L. Feng, A.B. Yu, Effect of liquid addition on the packing of mono-sized coarse spheres, Powder Technol. 99 (1998) 22-28.

[6] T.C. Halsey, A.J. Levine, How sandcastle fall, Phys. Rev. Lett. 80 (1998) 3141-3144.

[7] S. Herminghaus, Dynamics of wet granular matter, Adv. Phys. 54 (2005) 221-261.

[8] D.J. Hornbaker, R. Albert, I. Albert, A.-L. Barabasi, P. Schiffer, Nature (London) 387 (1997) 765

[9] G. Lian, C. Thornton, M.J. Adams, A theoretical study of the liquid bridge force between rigid spherical bodies, J. Colloid Interface Sci. 161 (1993) 3381-3391.

[10] H. Louati, D. Oulahna, A. de Ryck, Apparent friction and cohesion of a partially wet granular material in steady-state shear, Powder Technol. 278 (2015) 65-71.

[11] N. Lu, B. Wu, C. Tan, Tensile strength characteristics of unsaturated sands, J. Geotech. Geoenviron. Eng. 133 (2) (2007) 144-154.

[12] N. Mitarai, F. Nori, Wet granular materials, Adv. Phys. 55 (2006) 1-45.

[13] S.T. Nase, W.L. Vergas, A.A. Abatan, J.J. McCarthy, Discrete characterization tools for cohesive granular material, Powder Technol. 116 (2001) 214-223. 
[14] D. Oulahna, R. Collet, A. de Ryck, Mechanical resistance due to shearing of partially wet granular media, KONA 30 (2013) 109-118.

[15] P. Pierrat, H.S. Caram, Tensile strength of wet granular materials, Powder Technol. 91 (1997) 83-93.

[16] W. Pietsch, Agglomeration Process, Wiley-VCH, Weinheim, 2002.

[17] H. Rumpf, The tensile strength of granules and agglomerates, Intersci. Publ. (1962) 379-418.

[18] M. Scheel, R. Seemann, M. Brinkmann, M. Di Michiel, A. Sheppard, B. Breidenbach, S. Herminghaus, Morphological clues to wet granular pile stability, Nat. Mater. 7 (2008) 189-193.

[19] H. Schubert, Capillary forces: modeling and application in particulate technology, Powder Technol. 37 (1984) 105-116.
[21] J.P.K. Seville, C.D. Willett, P.C. Knight, Inter-particle forces in fluidisation: a review, Powder Technol. 113 (2000) 261-268.

[22] H.Y. Sohn, C. Moreland, The effect of particle size distribution on packing density, Can. J. Chem. Eng. 46 (1968) 162-167.

[23] M. Wu, S. Radl, J.G. Khinast, A model to predict liquid bridge formation between wet particles based on direct numerical simulations, AICHE J. 62 (2016) 1877-1897.

[24] A.B. Yu, J. Bridgwater, A. Burbidge, On the modelling of the packing of fine particles, Powder Technol. 92 (1997) 185-194.

[25] A.B. Yu, C.L. Feng, R.P. Zou, R.Y. Yang, On the relationship between porosity and interparticle forces, Powder Technol. 130 (2003) 70-76. 